\title{
Laser deposition and direct-writing of thermoelectric misfit cobaltite thin films
}

\author{
Jikun Chen (陈吉㫃), ${ }^{1}$ Alexandra Palla-Papavlu, ${ }^{1,2}$ Yulong Li, ${ }^{3}$ Lidong Chen, ${ }^{3}$ Xun Shi, ${ }^{3}$ \\ Max Döbeli, ${ }^{4}$ Dieter Stender, ${ }^{1}$ Sascha Populoh, ${ }^{5}$ Wenjie Xie, ${ }^{5}$ Anke Weidenkaff, ${ }^{5}$ \\ Christof W. Schneider, ${ }^{1}$ Alexander Wokaun, ${ }^{1}$ and Thomas Lippert ${ }^{1, a)}$ \\ ${ }^{1}$ Paul Scherrer Institute, General Energy Research Department, 5232 Villigen PSI, Switzerland \\ ${ }^{2}$ National Institute for Lasers, Plasma and Radiation Physics, Atomistilor 409, P.O. Box MG-36, ZIP-077125, \\ Bucharest, Romania \\ ${ }^{3}$ State Key Laboratory of High Performance Ceramics and Superfine Microstructure, Shanghai Institute of \\ Ceramics, Chinese Academy of Sciences, Shanghai, China \\ ${ }^{4}$ Labor für Ionenstrahlphysik, ETH Zürich, CH-8093 Zürich, Switzerland \\ ${ }^{5}$ EMPA—Solid State Chemistry and Catalysis, Dübendorf, Switzerland
}

(Received 29 April 2014; accepted 22 May 2014; published online 10 June 2014)

\begin{abstract}
A two-step process combining pulsed laser deposition of calcium cobaltite thin films and a subsequent laser induced forward transfer as micro-pixel is demonstrated as a direct writing approach of micro-scale thin film structures for potential applications in thermoelectric micro-devices. To achieve the desired thermo-electric properties of the cobaltite thin film, the laser induced plasma properties have been characterized utilizing plasma mass spectrometry establishing a direct correlation to the corresponding film composition and structure. The introduction of a platinum sacrificial layer when growing the oxide thin film enables a damage-free laser transfer of calcium cobaltite thereby preserving the film composition and crystallinity as well as the shape integrity of the as-transferred pixels. The demonstrated direct writing approach simplifies the fabrication of micro-devices and provides a large degree of flexibility in designing and fabricating fully functional thermoelectric micro-devices. (C) 2014 AIP Publishing LLC. [http://dx.doi.org/10.1063/1.4882423]
\end{abstract}

The thermoelectric (TE) effect gained considerable interest for prospective applications such as a solid-state electric power generator from temperature gradients or the operation as heat pumps for solid state refrigeration. ${ }^{1-3}$ In order to achieve a high performance of TE devices, two basic directions have been pursued: (i) the optimization of TE materials to achieve a high figure of merit $Z T\left(Z T=S^{2} \sigma T / \kappa\right.$; with $S$ as the Seebeck coefficient, $\sigma$ and $\kappa$ as the electrical and thermal conductivity, and the temperature $T$ ). ${ }^{1-3}$ (ii) TE devices with an optimized combination of $p$ - and $n$-TE materials with a well controlled aspect ratio $L / A$ of the single TE elements ( $A$ and $L$ represent the area and the thickness of a TE leg, respectively). ${ }^{4-13}$ Apart from the extensive investigations on bulk TE material and devices, ${ }^{1-5}$ TE thin films also received considerable attention ${ }^{6,13-23}$ due to the possibility to further optimize $Z T$ using low-dimensional effects such as quantum-confinement, ${ }^{13}$ phonon blocking/electron transmitting superlattice, ${ }^{14}$ or thermionic emission heterostructures. ${ }^{15}$ In addition, compared to traditional bulk TE devices, highly compact thin-film TE devices are favored for specific applications such as localized cooling of hotspots in microprocessors, ${ }^{6,7}$ micro-scaled power generators for micro-devices deployed on animal/human skin, ${ }^{6}$ or micro-/nano-scaled thermocouples for sensor applications. ${ }^{10,11}$

For the fabrication of micro-scaled TE electric devices, thin chalcogenide or oxides films are required. Thermoelectric oxides and chalcogenides often possess a complex elemental composition and crystal structure. Therefore, the prime issue to address is how to achieve the required film composition combined with the

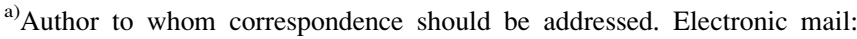
Thomas.Lippert@psi.ch
}

desired crystallinity to obtain high quality TE oxide films. ${ }^{16-24}$ From the commonly applied thin film deposition techniques, pulsed laser deposition (PLD) has the advantage to reliably maintain a stoichiometric transfer from a solid target to a substrate (see Fig. 1(a)). High quality TE thin films for a large range of compounds, such as $\mathrm{Sb}_{\mathrm{x}} \mathrm{Bi}_{2-\mathrm{x}} \mathrm{Se}_{\mathrm{y}} \mathrm{Te}_{3-\mathrm{y}},{ }^{16} \mathrm{Na}_{\mathrm{x}} \mathrm{CoO}_{2},{ }^{17}$ $\mathrm{Ca}_{3} \mathrm{Co}_{4} \mathrm{O}_{9},{ }^{18-22}$ doped-SrTiO ${ }_{3}{ }^{23}$ or filled-Skutterudites ${ }^{24}$ have been grown by PLD. For a micro-scaled TE device, a subsequent patterning step is required to define the shape of the $p$ - $/ n$-type TE films onto the same plane which can be achieved by microfabrication techniques, such as lithography and etching, ${ }^{6-11}$ or micromachining. ${ }^{12}$ These processes often require complex facilities involving high costs along with a reduced flexibility in device design. ${ }^{25}$ An alternative approach is laser-induced forward transfer (LIFT) ${ }^{26}$ (see Fig. 1(b)), a direct printing technique in which a laser beam is shaped and imaged onto the backside of a transparent support plate coated with the material to be transferred (also named donor). The laser partially vaporizes and subsequently transfers the donor material onto a receiver substrate which is usually in close proximity. The dimensions (e.g., length and width) and hence shape of the transferred material (also called pixel) is controlled by the imaged incident laser beam with a high spatial resolution of a few $\mu \mathrm{m}$ (see Fig. 1(b)). LIFT has been applied for patterning a wide range of materials for micro-devices such as OLEDs, or chemical sensors. ${ }^{26-30}$ Recently, $p$ - and $n$-doped chalcogenide thin films have been laser transferred by directly imaging the beam onto the donor. ${ }^{29}$ The as-transferred large area pixels showed some signs of thermal damage but remained largely intact in terms or their morphology, structure, and composition showing reduced but still reasonable thermoelectric properties as compared to the donor material. 
(a)
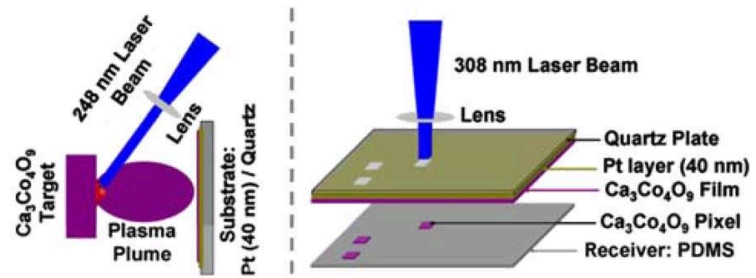

(b)

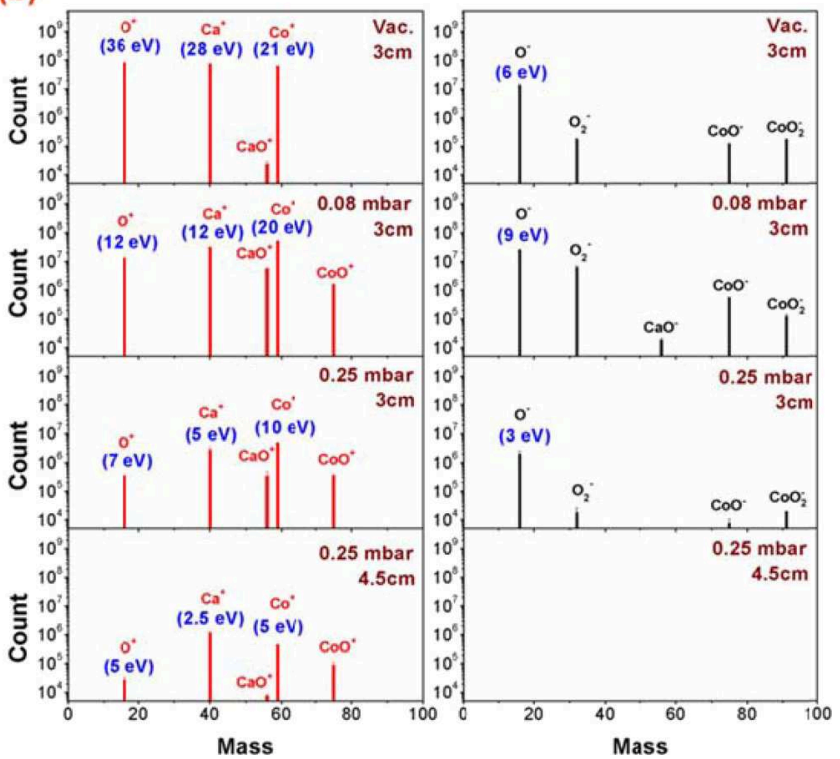

FIG. 1. (a) Schematic drawing of the pulsed laser deposition (left) and laser-induced forward transfer (right) working principles. (b) Total detected amount of the ionic plasma species in laser induced $\mathrm{Ca}_{3} \mathrm{Co}_{4} \mathrm{O}_{9}$ plasmas for the PLD process in four different background conditions. The average kinetic energies are marked for the principle ions in blue.

An alternative to chalcogenides are oxide TE materials due to their high chemical stability in, e.g., an oxidizing environment which enables a large application window. In this study, we present a two-step strategy for directly patterning the $n$-type $\mathrm{TE} \quad \mathrm{Ca}_{3} \mathrm{Co}_{4} \mathrm{O}_{9}$, also denoted as $\left[\mathrm{Ca}_{2} \mathrm{CoO}_{3}\right]^{\mathrm{RS}}\left[\mathrm{CoO}_{2}\right]_{1.62}{ }^{31}$ onto a flexible substrate using a combination of PLD for the thin film preparation and LIFT for materials transfer. The complexity in crystal structure and composition of $\mathrm{Ca}_{3} \mathrm{Co}_{4} \mathrm{O}_{9}$ is a challenge to grow using PLD and its mechanical hardness and brittleness for a successful transfer with LIFT. ${ }^{20,21}$ The $\mathrm{Ca}_{3} \mathrm{Co}_{4} \mathrm{O}_{9}$ possesses a layered structure: stacked $\mathrm{CdI}_{2}$-type $\mathrm{CoO}_{2}$ layers alternating with a rock-salt-type $\mathrm{Ca}_{2} \mathrm{CoO}_{3}$ layer along the c-axis. ${ }^{18-22}$ As illustrated in Fig 1(a), the $\mathrm{Ca}_{3} \mathrm{Co}_{4} \mathrm{O}_{9}$ film was first grown onto a transparent quartz substrate coated with a sputtered platinum (Pt) interlayer $(40 \mathrm{~nm})$ by PLD (Fig. 1(a)). In the second step, the $\mathrm{Ca}_{3} \mathrm{Co}_{4} \mathrm{O}_{9}$ film is transferred using LIFT onto a polymer receiver substrate (Fig. 1(b)) with the desired shape and size.

To optimize the deposition process for $\mathrm{Ca}_{3} \mathrm{Co}_{4} \mathrm{O}_{9}$ using PLD, the laser-induced plasma was monitored to understand the underlying plasma processes leading to the correct composition which is closely linked to the correct crystalline structure. Of interest are the ionic plasma composition and the kinetic energy distribution, $E_{\mathrm{K}}$, of the corresponding plasma species to adjust the materials composition to reach appropriate deposition conditions with respect to composition and structure. ${ }^{32,33}$ Details of the deposition parameters are given in the supplementary material. ${ }^{35}$ Using $E_{\mathrm{K}^{-}}$ resolved mass spectrometry, we are able to examine the amount and average kinetic energy $\left(E_{\mathrm{K}, \mathrm{Avr}}\right)$ of ionic plasma species (see supplementary material, ${ }^{35}$ Fig. S1). The results for different background pressures and substrate\&unknown_hyphen;target distances are summarized in Fig. 1(b) showing a large variation in the ionic plasma composition and $E_{\mathrm{K}, \mathrm{Avr}}$ when ablating $\mathrm{Ca}_{3} \mathrm{Co}_{4} \mathrm{O}_{9}$. These compositional variations in the plasma are also reflected in the corresponding optical appearance of the laser induced plasma plume (Fig. 2(a)).

In vacuum, the plasma consists mainly of charged atomic species $\left(\mathrm{Ca}^{+}, \mathrm{Co}^{+}, \mathrm{O}^{+}\right.$, and $\left.\mathrm{O}^{-}\right)$with large $E_{\mathrm{K}, \mathrm{Avr}}$ between 20 and $40 \mathrm{eV}$. The deposited films showed no pronounced film Bragg peaks in the X-ray diffraction (XRD) pattern and the film composition has the lowest oxygen content as determined using Rutherford Back Scattering (RBS). (a)

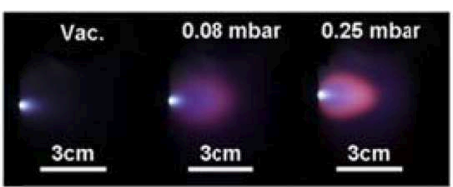

(c)

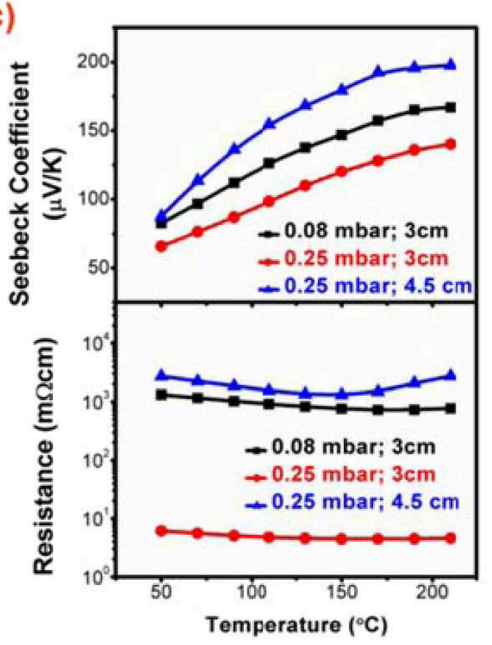

(b)

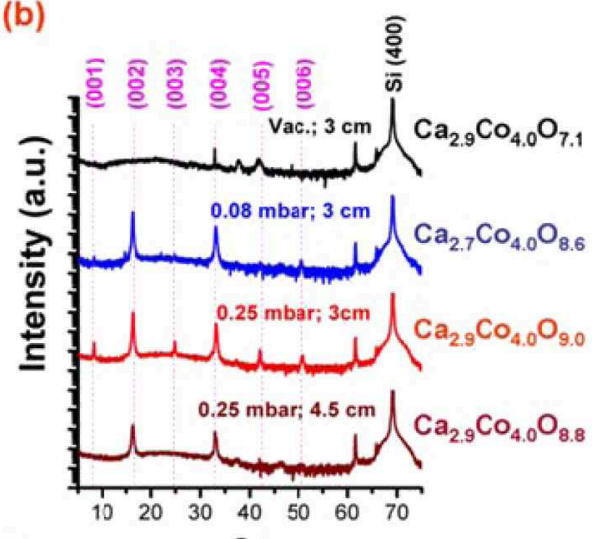

(d)

$2 \theta$

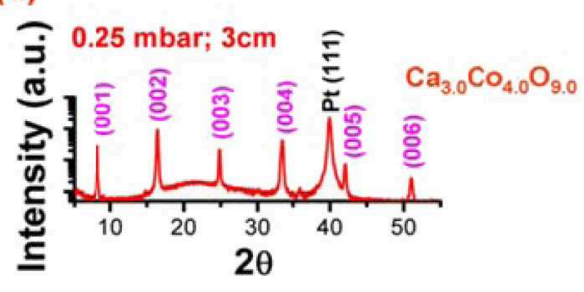

FIG. 2. (a) Photos of laser-induced plasma plume from a $\mathrm{Ca}_{3} \mathrm{Co}_{4} \mathrm{O}_{9}$ target at various background conditions. (b) XRD patterns and compositions of the as-deposited $\mathrm{Ca}_{3} \mathrm{Co}_{4} \mathrm{O}_{9}$ films in various background conditions. (c) Electric conductivity and Seebeck coefficient of the as-deposited $\mathrm{Ca}_{3} \mathrm{Co}_{4} \mathrm{O}_{9}$ films in various background conditions. (d) XRD of the $\mathrm{Ca}_{3} \mathrm{Co}_{4} \mathrm{O}_{9}$ donor film grown on Pt/quartz prior to LIFT. 
Reasons why the crystalline structure in the growing film was not obtained are sputtering effects due to the large $E_{\mathrm{K}}$ of the plasma species or too little oxygen was supplied from the target during the deposition and hence prevented the correct crystalline phase to be formed.

At 0.08 millibars $p \mathrm{O}_{2}$, the average $E_{\mathrm{K}}$ for the lighter $\mathrm{Ca}^{+}$and $\mathrm{O}^{+}$ions is reduced to $\sim 12 \mathrm{eV}$, while $E_{\mathrm{K}, \mathrm{Avr}}$ for $\mathrm{Co}^{+}$ was effectively unchanged. The plasma shows now a strong increase in $\mathrm{CaO}^{+}$and $\mathrm{CoO}^{+}$metal-oxygen ions due to the oxidization of the metallic species as a result of reactions with the background gas. In addition, the relative amount of $\mathrm{O}^{-}$compared to $\mathrm{O}^{+}\left(\mathrm{O}^{-} / \mathrm{O}^{+}: \sim 2\right)$ is strongly enhanced when compared to a vacuum deposition $\left(\mathrm{O}^{-} / \mathrm{O}^{+}: \sim 0.2\right)$. This can be attributed to either (1) an enhanced background formation of $\mathrm{O}^{-}$species or (2) a conversion of $\mathrm{O}^{+}$to $\mathrm{O}^{-}$or $\mathrm{O}$, respectively, originating from an electron attaching process. ${ }^{33}$ The first process, the formation of $\mathrm{O}^{-}$, requires a much lower formation energy $\left(\mathrm{O}_{2}+5.12 \mathrm{eV} \rightarrow 2 \mathrm{O} ; \mathrm{O}+\mathrm{e}^{-}\right.$ $\rightarrow \mathrm{O}^{-}+1.46 \mathrm{eV}$ ), compared to the formation of $\mathrm{O}^{+}$ $\left(\mathrm{O}+13.6 \mathrm{eV} \rightarrow \mathrm{e}^{-}+\mathrm{O}^{+}\right)$. With these plasma conditions, the prepared films shows a $\mathrm{Ca}_{\mathrm{x}} \mathrm{CoO}_{2}$ structure instead of the desired $\left[\mathrm{Ca}_{2} \mathrm{CoO}_{3}\right]^{\mathrm{RS}}\left[\mathrm{CoO}_{2}\right]_{1.62}$, where the $\mathrm{Ca}$ cation directly intercalates into the $\mathrm{CoO}_{2}$ layer without the formation of the rock-salt-type $\mathrm{Ca}_{2} \mathrm{CoO}_{3}$ layer. Compared to the desired $\left[\mathrm{Ca}_{2} \mathrm{CoO}_{3}\right]^{\mathrm{RS}}\left[\mathrm{CoO}_{2}\right]_{1.62}$, the $\mathrm{Ca}_{\mathrm{x}} \mathrm{CoO}_{2}$ structure is thermodynamically less stable but easier to form as a film (5.4 $\AA$ for $\mathrm{Ca}_{\mathrm{x}} \mathrm{CoO}_{2}, 10.8 \AA$ Á for $\mathrm{Ca}_{3} \mathrm{Co}_{4} \mathrm{O}_{9}$ ), a structure which also seems to be favored by a reduced supply of oxygen during growth. $^{20}$

When enhancing $p \mathrm{O}_{2}$ to 0.25 millibars and keeping the target-substrate distance at $3 \mathrm{~cm}$, the plasma plume just reaches the substrate position with the strongest confinement and emission intensity (Fig. 2(a)). Mass spectrometry reveals that $E_{\mathrm{K}, \mathrm{Avr}}$ of the ionic species is further reduced $(<10 \mathrm{eV})$ while the relative amount of $\mathrm{O}^{-}$compared to $\mathrm{O}^{+}$is largest $\left(\mathrm{O}^{-} / \mathrm{O}^{+} \sim 6\right)$. Under such plasma conditions, the desired $\left[\mathrm{Ca}_{2} \mathrm{CoO}_{3}\right]^{\mathrm{RS}}\left[\mathrm{CoO}_{2}\right]_{1.62}$ phase with a film composition of $\mathrm{Ca}_{2.9} \mathrm{Co}_{4} \mathrm{O}_{9.0}$ was observed for epitaxially grown films on $\mathrm{Si}$ and Pt-coated quartz. The XRD pattern for a $\mathrm{Ca}_{3} \mathrm{Co}_{4} \mathrm{O}_{9}$ film on Pt-coated quartz (Fig. 2(d)) shows a well $(00 l)$ oriented growth of the correct $\mathrm{Ca}_{3} \mathrm{Co}_{4} \mathrm{O}_{9.0}$ phase. Subsequent electrical transport measurements (Fig. 2(c)) show a similar resistance and comparable Seebeck coefficient as reported in Refs. 18-20. However, these films have not been prepared with respect to optimize TE properties. Our approach therefore demonstrates that with the selected plasma conditions, $\mathrm{Ca}_{3} \mathrm{Co}_{4} \mathrm{O}_{9}$ films with a proper composition and acceptable transport properties can be prepared at a deposition temperature of $6500^{\circ} \mathrm{C}$.

By increasing the target-substrate distance to $4.5 \mathrm{~cm}$ at 0.25 millibars $p \mathrm{O}_{2}$, the plasma plume is not reaching the substrate and the lowest amount of species as well as a further reduced $E_{\mathrm{K}, \mathrm{Avr}}$ is observed. Atomic oxygen is almost absent and the very low concentration is attributed to the fact that light elements are scattered more strongly than heavier metallic species and are therefore lost from the plasma cloud reaching the substrate. These films show again a $\mathrm{Ca}_{\mathrm{x}} \mathrm{CoO}_{2}$ phase instead of the desired structure despite being almost fully stoichiometric $\left(\mathrm{Ca}_{2.9} \mathrm{Co}_{4} \mathrm{O}_{8,8}\right)$. This leads to the conclusion that the correct crystalline structure of $\mathrm{Ca}_{3} \mathrm{Co}_{4} \mathrm{O}_{9}$ is very sensitive to the correct oxygen content and a high concentration of $\mathrm{O}^{-}$is necessary to support the formation of the proper crystalline modification.

A LIFT procedure as described in Ref. 29 turns the astransferred continuous oxide film into powder upon impact on the receiver due to the mechanical hardness and brittleness of $\mathrm{Ca}_{3} \mathrm{Co}_{4} \mathrm{O}_{9}$. The LIFT procedure was therefore optimized to avoid (i) a direct laser interaction by introducing a thin Pt film as a sacrificial layer to absorb the laser light and (ii) introducing a soft substrate, i.e., polydimethylsiloxane (PDMS) to reduce the stress on the pixel upon transfer. ${ }^{29,30}$ For the LIFT transfer of $\mathrm{Ca}_{3} \mathrm{Co}_{4} \mathrm{O}_{9}$, the optimized deposition conditions $\left(p \mathrm{O}_{2}=0.25\right.$ millibars, $d=3 \mathrm{~cm}, F=1.2 \mathrm{~J} \mathrm{~cm}^{-2}$ ) are used to grow $\sim 100 \mathrm{~nm}$ thick films of $\mathrm{Ca}_{3} \mathrm{Co}_{4} \mathrm{O}_{9}$ on $\mathrm{Pt} /$ quartz.

The laser ablation fluence $F$ for transfer is further optimized over a broad range of $0.2-1 \mathrm{~J} \mathrm{~cm}^{-2}$ for a laser wavelength of $308 \mathrm{~nm}$. The optical images of $\mathrm{Ca}_{3} \mathrm{Co}_{4} \mathrm{O}_{9}$ micro-pixels obtained immediately after transfer at different laser fluences are displayed in Figs. 3(a)-3(d). For $F<0.45 \mathrm{~J}$ $\mathrm{cm}^{-2}$, no transfer occurs. At $0.45 \mathrm{~J} \mathrm{~cm}^{-2}$, a pixel from the donor is transferred onto the receiving substrate as seen in

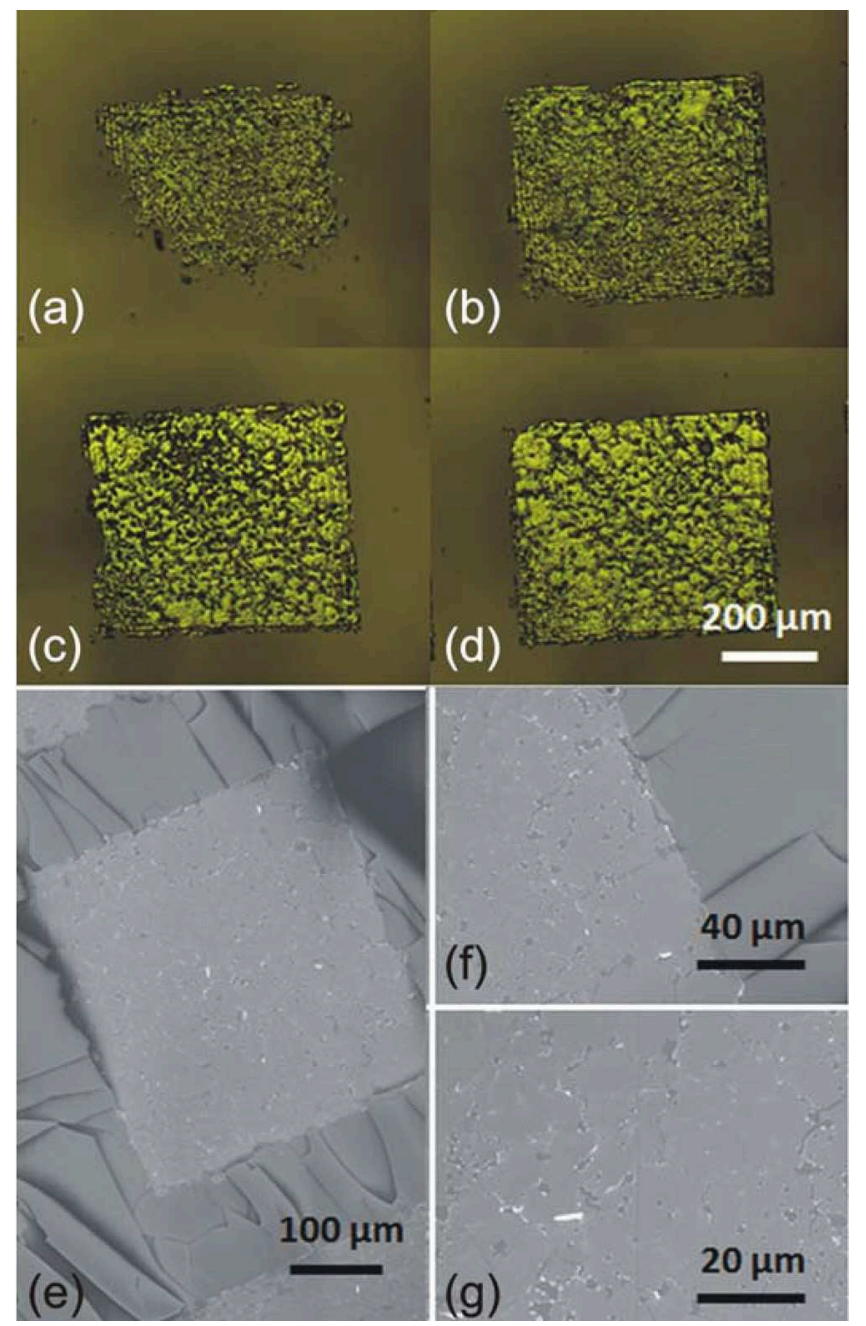

FIG. 3. $\mathrm{Ca}_{3} \mathrm{Co}_{4} \mathrm{O}_{9}$ micro-pixels deposited onto PDMS substrate at different laser fluences (a) $450 \mathrm{~mJ} \mathrm{~cm}^{-2}$, (b) $500 \mathrm{~mJ} \mathrm{~cm}^{-2}$, (c) $550 \mathrm{~mJ} \mathrm{~cm}^{-2}$, (d) 600 $\mathrm{mJ} \mathrm{cm}{ }^{-2}$. SEM image of (e) a $\mathrm{Ca}_{3} \mathrm{Co}_{4} \mathrm{O}_{9}$ micro-pixel deposited at $600 \mathrm{~mJ}$ $\mathrm{cm}^{-2}$ laser fluence, (f) the edge of the pixel shown in (e), and (g) the middle part of the pixel shown in (e). 
Fig. 3(a). However, the pixels transferred at this laser fluence have an inhomogeneous shape and are laterally not well resolved. For the fabrication of a micro-device, it is very important to control both the size and shape of the transferred spot. In Figs. 3(b)-3(d), micro-pixels transferred with different laser fluences $\left(500-600 \mathrm{~mJ} \mathrm{~cm}^{-2}\right)$ are shown. All the shown pixels are $\sim 500 \times 500 \mu \mathrm{m}^{2}$ but in some cases the edges are less uniform, e.g., the left bottom corner at $500 \mathrm{~mJ}$ $\mathrm{cm}^{-2}$. This is probably due to a pulse to pulse energy variation of the laser. All transferred pixels are regularly arranged. In the case of bismuth telluride pixels obtained by LIFT, ${ }^{29}$ the reported laser fluence for optimal transfer of $1 \mu \mathrm{m}$ thick pixels with $\lambda=248 \mathrm{~nm}$ is $\sim 100 \mathrm{~mJ} \mathrm{~cm}^{-2}$. The difference in fluence for bismuth telluride and $\mathrm{Ca}_{3} \mathrm{Co}_{4} \mathrm{O}_{9}$ is mainly related to the energy required to evaporate the sacrificial Pt-layer in order to move the brittle layer and the hardness of the transferred oxide. Using a sacrificial layer, the transfer of oxide layers with a thickness of $0.5 \mu \mathrm{m}$ is possible.

Scanning electron microscopy (SEM) images were acquired to assess modifications of the micro-pixel morphology caused by the absorption of the laser pulse. A SEM image of a transferred pixel (at $600 \mathrm{~mJ} \mathrm{~cm}^{-2}$ ) is shown in Fig. 3(e). The SEM images with higher magnification of the middle part and edge of the same pixel (shown in Figs. 3(f) and $3(\mathrm{~g})$ reveal that the $\mathrm{Ca}_{3} \mathrm{Co}_{4} \mathrm{O}_{9}$ is immobilized on the PDMS substrate. The transferred micro-pixel is homogeneous, with well defined edges (see Fig. 3(f)). The micro-pixel has a clean surface with no visible changes in the morphology or debris from the Pt interlayer (see Fig. 3(g)).

The following question to address is whether there is an influence on structure and composition of the $\mathrm{Ca}_{3} \mathrm{Co}_{4} \mathrm{O}_{9}$ micro-pixels caused by a possible heat-transfer during the LIFT process. A composition of the pixel after the LIFT transfer of $\mathrm{Ca}_{3.2 \pm 0.3} \mathrm{Co}_{4} \mathrm{O}_{9}$ has been measured for single pixels which compares well to the composition of the donor film $\left(\mathrm{Ca}_{3.0 \pm 0.15} \mathrm{Co}_{4} \mathrm{O}_{9}\right)$ before material transfer. The oxygen content has a major influence on the thermoelectric properties of misfit cobaltites ${ }^{34}$ but is difficult to determine due to the small pixel size and small amount of pixel material (see supplementary material ${ }^{35}$ ). Some $\mathrm{Pt}$ is also detected in the RBS spectrum. From the position in the spectrum, it can be concluded that the Pt forms a discontinuous layer on the surface of the pixel as verified by SEM. Due to the evaporation of $\mathrm{Pt}$ as a sacrificial layer, we find nano-sized metallic droplets on the transferred pixel indicating that Pt has coalesced to small particles after the transfer and thus should not have a negative influence on the TE properties of $\mathrm{Ca}_{3} \mathrm{Co}_{4} \mathrm{O}_{9}$ micro-pixels. We observe both (001) and (002) diffraction peaks in the XRD pattern (see supplementary material, ${ }^{35}$ Fig. S2) of as-transferred pixels. This is a direct indication that the crystal structure was preserved during and after the LIFT process.

In conclusion, a combined process of PLD and LIFT has been used for direct patterning of $\mathrm{Ca}_{3} \mathrm{Co}_{4} \mathrm{O}_{9}$ TE microscaled pixels for potential applications in TE micro-devices. To obtain the best PLD deposition conditions for the growths of $\mathrm{Ca}_{3} \mathrm{Co}_{4} \mathrm{O}_{9}$ thin films, plasma mass spectrometry has been applied. Through $E_{\mathrm{K}}$-resolved mass spectrometry analysis, we established the correlation between $p \mathrm{O}_{2}$, plasma properties and film properties, in particular, the value of $\mathrm{O}^{-}$for the formation of the correct structure. A Pt sacrificial layer is introduced for the transfer of $\mathrm{Ca}_{3} \mathrm{Co}_{4} \mathrm{O}_{9}$ as a micro-pixel to avoid the direct laser interaction with the TE material thereby preserving composition, structure, and shape of the transferred pixel. This is unlike directly transferred pixels where a structural and compositional change can occur due to the intense laser-matter interaction. Compared to conventional patterning processes, e.g., optical lithography or micro-machining, the LIFT procedure simplifies the fabrication of complex TE micro-scaled devices. In addition, the cross section of as-transferred patterns can be conveniently adjusted via the laser beam shape and the Pt-sacrificial layer has no detrimental effects on the as-transferred material. The demonstrated approach for the direct pattering of the $p$-type TE $\mathrm{Ca}_{3} \mathrm{Co}_{4} \mathrm{O}_{9}$ can be extended to other materials in order to fabricate fully functional thermoelectric micro-devices on soft, biocompatible substrates.

This work was partially supported by SNF (Project No. 200021-134577) as well as the National Natural Science Foundation of China (Project Nos. 51121064 and 51222209) and the Nanotechnology Project of Shanghai Science and Technology Committee (Project No. 11nm0502800). We also would like to thank S. Temmel with SEM characterization.

${ }^{1}$ M. S. Dresselhaus, G. Chen, M. Y. Tang, R. G. Yang, H. Lee, D. Z. Wang, Z. F. Ren, J. P. Fleurial, and P. Gogna, Adv. Mater. 19, 1043 (2007).

${ }^{2}$ R. Robert, S. Romer, A. Reller, and A. Weidenkaff, Adv. Eng. Mater. 7, 303 (2005).

${ }^{3}$ Y. Pei, A. F. May, and G. J. Snyder, Adv. Energy Mater. 1, 291 (2011).

${ }^{4}$ K. Koumoto, R. Funahashi, E. Guilmeau, Y. Miyazaki, A. Weidenkaff, Y. Wang, and C. Wan, J. Am. Ceram. Soc. 96, 1 (2013).

${ }^{5}$ R. Funahashi, S. Urata, K. Mizuno, T. Kouuchi, and M. Mikami, Appl. Phys. Lett. 85, 1036 (2004).

${ }^{6}$ R. Venkatasubramanian, E. Siivola, T. Colpitts, and B. O'Quinn, Nature 413, 597 (2001).

${ }^{7}$ A. Majumdar, Nat. Nanotechnol. 4, 214 (2009).

${ }^{8}$ G. E. Bulman, E. Siivola, B. Shen, and R. Venkatasubramanian, Appl. Phys. Lett. 89, 122117 (2006).

${ }^{9}$ N. Wang, L. Han, H. He, N. H. Park, and K. Koumoto, Energy Environ. Sci. 4, 3676 (2011).

${ }^{10}$ M. Z. Yang, C. C. Wu, C. L. Dai, and W. J. Tsai, Sensors 13, 2359 (2013).

${ }^{11}$ T. Huesgen, P. Woias, and N. Kockmann, Sens. Actuators, A 145-146, 423 (2008).

${ }^{12}$ J. Su, V. Leonov, M. Goedbloed, Y. Andel, M. C. Nooijer, R. Elfrink, Z. Wang, and R. J. M. Vullers, J. Micromech. Microeng. 20, 104005 (2010).

${ }^{13}$ L. D. Hicks and M. D. Dresselhaus, Phys. Rev. B 47, 12727 (1993).

${ }^{14}$ S. M. Lee, D. G. Cahill, and R. Venkatasubramanian, Appl. Phys. Lett. 70, 2957 (1997).

${ }^{15}$ G. D. Mahan and L. M. Woods, Phys. Rev. Lett. 80, 4016 (1998).

${ }^{16}$ A. L. Bassi, A. Bailini, C. S. Casari, F. Donati, A. Mantegazza, M. Passoni, V. Russo, and C. E. Bottani, J. Appl. Phys. 105, 124307 (2009).

${ }^{17}$ P. Brinks, B. Kuiper, E. Breckenfeld, G. Koster, L. W. Martin, G. Rijnders, and M. Huijben, Adv. Energy Mater. 4, 1301927 (2014).

${ }^{18}$ Y. F. Hu, W. D. Si, E. Sutter, and Q. Li, Appl. Phys. Lett. 86, 082103 (2005).

${ }^{19}$ H. W. Eng, W. Prellier, S. Hébert, D. Grebille, L. Méchin, and B. Mercey, J. Appl. Phys. 97, 013706 (2005).

${ }^{20}$ T. Sun, H. H. Hng, Q. Yan, and J. Ma, J. Electron. Mater. 39, 1611 (2010).

${ }^{21}$ H. Ohta, K. Sugiura, and K. Koumoto, Inorg. Chem. 47, 8429 (2008).

${ }^{22}$ D. Pravarthana, O. I. Lebedev, S. Hebert, D. Chateigner, P. A. Salvador, and W. Prellier, Appl. Phys. Lett. 103, 143123 (2013).

${ }^{23}$ S. Ohta, T. Nomura, and H. Ohta, Appl. Phys. Lett. 87, 092108 (2005).

${ }^{24}$ J. C. Caylor, A. M. Stacya, R. Gronsky, and T. Sands, J. Appl. Phys. 89, 3508 (2001).

${ }^{25}$ A. Campo and E. Arzt, Chem. Rev. 108, 911 (2008). 
${ }^{26}$ C. B. Arnold, P. Serra, and A. Piqué, MRS Bull. 32, 23 (2007).

${ }^{27}$ C. Boutopoulos, E. Touloupakis, I. Pezzotti, M. T. Giardi, and I. Zergioti, Appl. Phys. Lett. 98, 093703 (2011).

${ }^{28}$ F. Di Pietrantonio, M. Benetti, D. Cannatà, E. Verona, A. Palla-Papavlu, V. Dinca, M. Dinescu, T. Mattle, and T. Lippert, Sens. Actuators, B 174, 158 (2012).

${ }^{29}$ M. Feinaeugle, C. L. Sones, E. Koukharenko, B. Gholipour, D. W. Hewak, and R. W. Eason, Appl. Phys. A 112, 1073 (2013).

${ }^{30}$ M. Feinaeugle, C. L. Sones, E. Koukharenko, and R. W. Eason, Smart Mater. Struct. 22, 115023 (2013).
${ }^{31}$ A. C. Masset, C. Michel, A. Maignan, M. Hervieu, O. Toulemonde, F. Studer, B. Raveau, and J. Hejtmanek, Phys. Rev. B 62, 166 (2000).

${ }^{32}$ C. Aruta, S. Amoruso, R. Bruzzese, X. Wang, D. Maccariello, F. Miletto Granozio, and U. Scotti di Uccio, Appl. Phys. Lett. 97, 252105 (2010).

${ }^{33}$ M. Esposito, M. Bator, M. Döbeli, T. Lippert, C. W. Schneider, and A. Wokaun, Appl. Phys. Lett. 99, 191501 (2011).

${ }^{34}$ D. Moser, M. G. Garnier, L. Karvonen, A. Shkabko, P. Aebi, and A. Weidenkaff, J. Mater. Sci. 48, 2823 (2013).

${ }^{35}$ See supplementary material at http://dx.doi.org/10.1063/1.4882423 for experimental details on film deposition and plasma properties. 